\title{
A Comparative Study of Outranking Methods for Multi-Criteria Optimization of Electromechanical Modules
}

\author{
Ina D. NIKOLOVA, Hirpa G. LEMU, Dimitrinka S. DAHTEROVA, Vanio D. IVANOV
}

\begin{abstract}
The paper presents a comparative assessment of the procedures for applying two outranking methods in solving multi-criteria optimization tasks. The conducted study compares the fundamental PROMETHEE (Preference Ranking Organization METHod for Enrichment Evaluations) method, which is widely proposed to support selection of the best compromise alternative in multi-criteria tasks, with the newly developed RAZOR (Ranking of Alternatives by Z-score Operation Ratings) method. The paper describes the ranking methods and provides demonstrative numerical examples for existing electromechanical modules. The results of the numerical examples from the conducted multi-criteria optimization on a number of given criteria are presented. The study demonstrated that the calculation procedure in PROMETHEE method demands certain level of preliminary knowledge, but provides fine setting of preferences by the decision-maker. The RAZOR method, on the other hand, demands no preliminary knowledge and it is easier to visualize graphically.
\end{abstract}

Keywords: electromechanical modules; multi-criteria optimization; PROMETHEE II; RAZOR; z-score

\section{INTRODUCTION}

In the design process of modern electro-mechanical systems, optimization plays a very important role, in particular, in achieving a functional and reliable system that fully meets preliminary specified requirements. The main component of an electromechanical system is the electromechanical drive module, which represents constructive unification of the electrical and the mechanical part of the system. In most cases, it is a combination between an electric motor and a gear reducer (the so-called, in practice, geared motors). An exemplary structural scheme of such module is given in Fig. 1. As illustrated in the figure a clutch can be used as a connection element, although most companies that manufacture such modules generally use different types of adapters. The vast amount of possible applications of these drive modules, such as woodworking machinery, textile machinery, HVAC, chemical industry, conveyor systems, garage doors, etc., as well as the continuous development of new technologies and technological products enforce the need for constant research of new methodologies for their design and optimal selection.

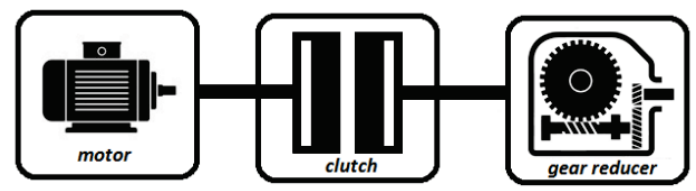

Figure 1 Electromechanical module - exemplary structural scheme

Both tasks for designing electromechanical modules (EMM) and for optimal selection of existing ones for a given application are multi-variate, which is the main motivation for conducting this research.

Modern electromechanical drive systems are designed based on the modular approach. The main purpose of this approach is to be able to build as great a number of machines/systems as possible that can be used in different application areas using as small as possible number of unified modules. Due to its advantages, the modular design approach has been used for many years in different fields, such as electric vehicles [1], robots and manipulators [2], wind turbines [3], machine tools [4], buildings [5] and road embankments [6]. Modular design concept finds application in the design of EMM and most of the renowned companies that produce such drives have integrated the concept into their manufacturing technology as early as the $1920 \mathrm{~s}$ [7]. The numerous advantages that this approach offers such as reducing the design and manufacturing time and costs, increasing the flexibility and the design possibilities, as well as the reliability of the systems and the quality of the products, etc., are some of the reasons for its wide application in vast variety of areas.

Although there are some requirements and limitations that need to be met when combining different types and sizes of electric motors and gear reducers, a significant number of combinations can be archived at constant values for the input data (rotational speed of the output shaft in [RPM] and the torque on the output shaft in [Nm]). In order to select the most appropriate variant for a given application, an optimal solution by a given target function needs to be found, i.e. an optimization of the alternatives needs to be carried out, which is proven to be a difficult task that engineers face on a daily basis.

The definition of the optimality concept is application dependent. It, in general, implies selection of or making decision on the most favourable result under specific limitations or conditions. For instance, Zeleni [8] proposed eight concepts of optimality that provide a framework for conducting multi-criteria decision-making analysis. In addition, the real-life optimization problems in their essence, are multi-criterial, i.e. the decision-maker has to select the optimal solution among many alternatives dictated by a number of criteria, which are often contradicting. The multi-criteria optimization task does not provide one single solution, but rather a number of possible solutions, which are weighted by the decision-maker. The decision-making process is considerably eased by usage of the developed multi-criteria decision analysis (MCDA) tools, which include different methodologies and software.

In general, the classical multi-criteria methodologies can be divided into three main groups [9]: (1) multiattribute value theory, (2) outranking methods and (3) interactive methods. 
There exists a general assumption that there are no better or worse methodologies, but methodologies that are better suited to particular decision problems than others [10]. Furthermore, we find in the literature that ideas have been proposed to unify several multi-objective optimization methods that can be used sequentially with the option of switching between procedures during the optimization process [11]. This approach means that different ways can be used to express preference needs and the active participation of the decision-maker during the switching between the procedures is required, i.e. the decision-maker must have some preliminary in-depth knowledge of the methods involved [12]. The family of outranking methods is considered well suited for provision of insight into the nature of multi-criteria decision problems and they provide suitable methodology to solve the task for optimization of EMM.

The study presented in this article is conducted using the fundamental PROMETHEE II method and the newly developed RAZOR method. The two methods can be easily applied in optimization of large number of alternatives, as both of them offer accurate ranking and opportunity for graphical interpretation of the results. In Section 2 of the paper, the PROMETHEE II methodology has been described with its most underlining concepts. Further detailed information on the calculus apparatus of the method can be found elsewhere in the literature $[13,14]$. Under the same section, the procedure and calculus of the RAZOR method, which is a newly developed outranking technique, are presented. In Section 3, calculation on demonstrative examples for existing electromechanical modules is conducted and the results of the optimization using both methods are presented. Upon providing a short analysis of the obtained results in Section 4, concluding remarks are given in Section 5.

\section{METHODOLOGY}

As indicated above, the article focuses on comparative study of two decision-making tools, viz. PROMETHEE II and RAZOR, to perform multi-criteria optimization of electromechanical modules. In this section, the underlying principles of both methods are first elaborated.

\subsection{PROMETHEE Method}

Since its introduction in the 1980s, the PROMETHEE method has represented a fundamental methodology for solving multi-criteria optimization tasks. As a result various studies have been conducted and numerous variations of the method, including PROMETHEE I, II, III, IV, $\mathrm{V}$ and VI have been proposed $[15,16]$.

Multiple software products and add-ins have been developed with the aim to facilitate the decision-making and calculation processes. Among others, the following can be mentioned as examples:

- Extensions for MS Excel such as DEA Excel Solver [17], Xtreme by Optimal Computing, [18]), GeneHunter by Ward Systems Group Inc., [19], SolveXl by Exeter Advanced Analytics LLP [20]. - Optimization toolboxes ${ }^{\mathrm{TM}}$ for MATLAB $[12,21]$.

- $\quad$ Specialized software [22], Visual PROMETHEE [23], Decision Deck Diviz [24].
Nevertheless, the basis of the methodology is still used in its original form. The method uses weights and preference functions that allow proper decision-making particularly for too large optimization criteria [25].

Further details on the historical backgrounds and contributions of the method are given in the comprehensive review presented in [26]. Review of the available literature shows as well that the PROMETHEE method and its extensions have been used widely in many different applications [14, 27, 28].

Pairwise comparison and preference: This is the basis of the method where the calculated differences between each pair of alternatives are compared. These differences are evaluated with especially introduced preference functions. The decision-maker plays the strongest role at this stage. The outcome of the ranking depends on the selection of the type of preference function(s) to be used and the selection of values for the corresponding threshold(s). Since there exists no single solution to a multi-criteria optimization task, but rather several possible solutions, the preference that the decision-maker expresses is of the upmost importance. The PROMETHEE can be used successfully as MCDA tool if the decision-maker can express his/her preferences for the selected criteria.

Weights: Depending on the importance of a criterion, according to the decision-maker preference, weights of the criteria can be formulated. There are various methods of determining weight coefficients, as the PROMETHEE method allows equal importance of each criterion.

Preference degree and ranking: PROMETHEE offers the calculation of preference degree of one alternative $a_{i}$ over another alternative $a_{j}$, which is used for the ranking of the alternatives based on the so-called positive and negative flows, respectively $\varphi^{+}$and $\varphi^{-}$. There are two main approaches for ranking of the alternatives:

PROMETHEE I - the positive and negative flows are used to gain a partial pre-order. The larger $\varphi^{+}\left(a_{i}\right)$, the more the alternative dominates the other alternatives. The smaller $\varphi^{-}\left(a_{i}\right)$, the less the alternative is dominated.

PROMETHEE II - complete ranking can be achieved by considering the net flow $\varphi\left(a_{i}\right)$ for each alternative. If $\varphi\left(a_{i}\right)>\varphi\left(a_{j}\right)$, then $a_{i}$ outranks $a_{j}$. If $\varphi\left(a_{i}\right)=\varphi\left(a_{j}\right)$, then $a_{i}$ is indifferent to $a_{j}$. Fig. 2 shows the overall steps involved in the implementation of the PROMETHEE II method.

The PROMETHEE II method has been selected for conducting the presented study. Compared to the other versions, which can be viewed as extensions of the original methodology, PROMETHEE II offers complete ranking of the alternatives (pre-order) and it has the highest similarity with the newly developed RAZOR method.

\subsection{RAZOR}

The RAZOR method is a newly developed methodology for alternatives ranking based on the statistical Z-standardization approach. The basics of the method is the possibility to measure the distance up to the arithmetical average with the help of the standard deviation, which in statistics is called Z-standardization or $Z$-normalization. The values measured using this approach are called $Z$-values or most commonly referred to as standard score or Z-score. 
The standard score is a very useful statistics because it allows the probability of a score occurring within a normal distribution to be calculated and enables the comparison of two scores that are from different normal distributions [29]. This statistical approach finds application in various fields such as medicine [30, 31], financial and banking sector [32], computer technology [33], educational assessment [34], and the like. The main advantage of this approach is that it allows non-comparable distribution values to be equalized to one scale, so they can be compared.

While implementing the RAZOR method, there is no need for selection of type of preference function to work with or to define values for the corresponding thresholds, which can be pointed out as another advantage, as the decision-maker's work is considerably facilitated. Figure 3 shows the procedure for conducting optimization with RAZOR method.

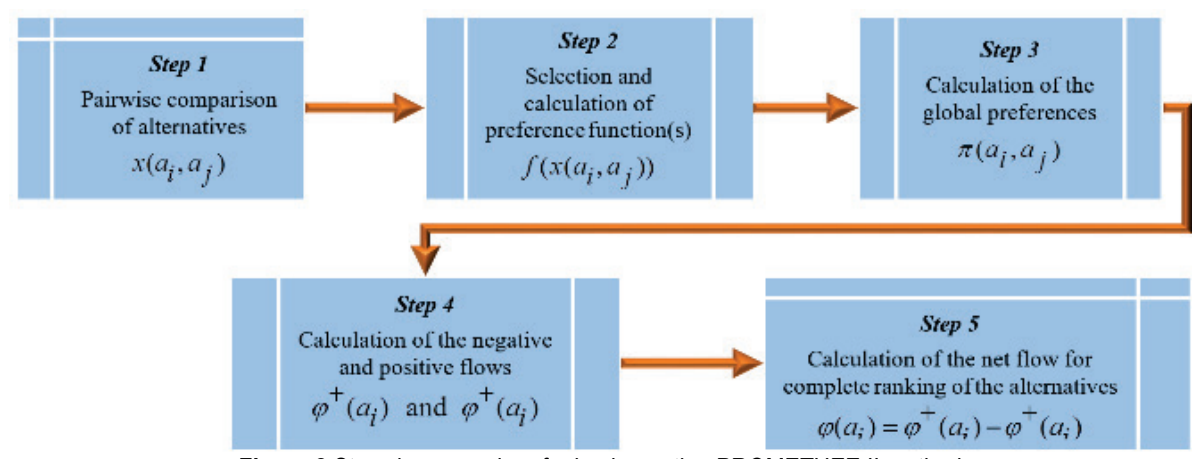

Figure 2 Stepwise procedure for implementing PROMETHEE II method

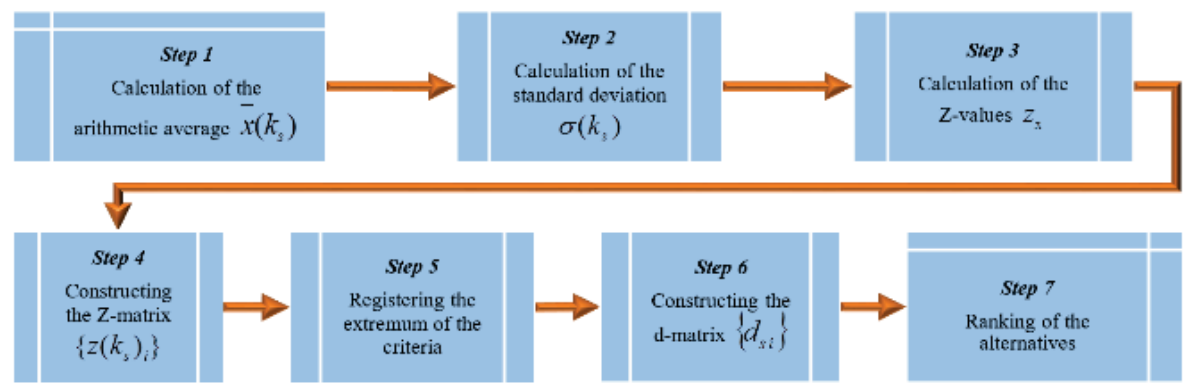

Figure 3 Stepwise procedure for implementing RAZOR method

The following multi-criteria task is considered for the method:

$$
\begin{aligned}
& \operatorname{Opt}\{k(a)\}=\operatorname{Extr}\left\{k_{1}(a), k_{2}(a), \ldots, k_{h}(a), \ldots, k_{n}(a)\right. \\
& a \in K
\end{aligned}
$$

The RAZOR method can be applied in solving the given optimization task by implementing the steps described in Fig. 3 and presented in the following steps.

Step 1. Defining arithmetic average for criteria $k_{i}($.$) :$

$\bar{x}\left(k_{s}\right)=\frac{1}{m} \sum_{i=1}^{m} k_{s}\left(a_{i}\right), \forall s=1,2, \ldots, n$

where $m$ is the number of the selected alternatives.

Step 2. Calculation of the standard deviation for the criteria $k_{i}($.$) , based on the calculated value for the$ arithmetic average:

$$
\sigma\left(k_{s}\right)=\sqrt{\frac{1}{m-1} \sum_{i=1}^{m}\left(k_{s}\left(a_{i}\right)-\bar{x}\left(k_{s}\right)\right)^{2}}, \quad \forall s=1,2, \ldots, n
$$

Step 3. Calculation of Z-values using the dependence:

$$
z_{x}=\frac{x-\bar{x}}{\sigma}
$$

where $x$ is a concrete value from the distribution (the data row), $\bar{x}$ is the arithmetic average of this distribution, and $\sigma$ is the standard deviation of the same distribution.

Step 4. Creating the so-called Z-matrix $\left\{z\left(k_{s}\right)_{i}\right\}$ from:

$z\left(k_{s}\right)_{i}=\frac{k_{s}\left(a_{i}\right)-\bar{x}\left(k_{s}\right)}{\sigma\left(k_{s}\right)}, \begin{aligned} & \forall s=1,2, \ldots, n \\ & \forall i=1,2, \ldots, m\end{aligned}$

Step 5. Registration of the extremum of the criteria $k_{i}($. above $\boldsymbol{A}$ :

$$
\begin{array}{ll}
\bar{k}_{s}=\operatorname{Extr}\left\{k_{s}\left(a_{1}\right), k_{s}\left(a_{2}\right), \ldots, k_{s}\left(a_{m}\right)\right\}, & \forall s=1,2, \ldots, n \\
\bar{z}_{s}=\operatorname{Extr}\left\{z\left(k_{s}\right)_{1}, z\left(k_{s}\right)_{2}, \ldots, z\left(k_{s}\right)_{i}\right\}, & \forall s=1,2, \ldots, n \\
& \forall i=1,2, \ldots, m
\end{array}
$$

The so-called "Ideal alternative" vector is obtained, which is built from the extremums of the components $k_{i}($.$) of the$ criteria $k_{i}($.$) :$

$$
\overline{K(A)}=\left(\overline{k_{1}}, \overline{k_{2}}, \ldots, \overline{k_{n}}\right)
$$

Step 6. Based on the calculated values of the Z-matrix, another matrix, called d-matrix, is constructed. It is a matrix with the distances from each alternative to the "Ideal alternative": 
$d_{s i}=\left|z\left(k_{s}\right)_{i}-z\left(\overline{k_{s}}\right)_{i}\right|=\left|\frac{k_{s}\left(a_{i}\right)-\overline{k_{s}}}{\sigma\left(k_{s}\right)}\right|, \quad \begin{aligned} & \forall i=1,2, \ldots, m \\ & \forall s=1,2, \ldots, n\end{aligned}$

Step 7. At the final step, the ranking of the alternatives is defined based on the following expression:

$R_{i}^{n}=\sum_{s=1}^{n} d_{s i} \cdot w_{i}$

where $w_{i}$ is the weight coefficient $\left(w_{i}=0-1\right)$. Regarding optimality on the $n$ criteria, alternative $a_{i}$ will dominate alternative $a_{j}$, if $R_{i}^{n} \geq R_{j}^{n}$.

\section{DEMONSTRATIVE EXAMPLES}

A multi-criteria optimization of existing geared motors (EMM) of three German companies has been conducted: (1) KEB Antriebstechnik GmbH, (2) WATT Drive Antriebstechnik GmbH and (3) Getriebebau NORD $\mathrm{GmbH}$. The selection of alternatives is based on the following input data: output speed $n_{\text {out }}=130 \mathrm{rpm}$ and output torque $M_{\text {out }}=77 \mathrm{~N} \cdot \mathrm{m}$. The input power $P_{\text {in }}$ and the output power $P_{\text {out }}$ are calculated to be $P_{\text {in }}=1,09 \mathrm{~kW}$ and $P_{\text {out }}=1,05 \mathrm{~kW}$ respectively. An electric motor with nominal power $P_{\text {nom }}=1,10 \mathrm{~kW}$ will be able to ensure that the values of the input data can be achieved. Based on these values, forty-nine (49) combinations of electric motor-gear reducers were selected using the manufacturers' product catalogue and selection software. Their structural components are asynchronous squirrel cage motor (2-, 4-, 6- and 8-pole motors are available) with nominal power of $1,10 \mathrm{~kW}$ and a gear reducer (helical, bevel, worm, with parallel shafts and combined gear units). The main technical parameters of the selected geared motors are given in Tab. 1 .

The multi-criterial analysis of electromechanical modules can be conducted based on two main groups of criteria: (1) static criteria and (2) dynamic criteria. The static criteria include geometrical, energy and economical characteristics of the modules such as the total volume of the module, its overall dimensions, its total weight, the total efficiency, the centre distance between the gear reducer of input and output shaft, comparative values assessment, etc. The dynamic criteria represent some of the EMM dynamic characteristics such as fast performance, degree of uniformity in the starting regime, coefficient of dynamic overload in starting regime, the deviation of the torque, etc. For the demonstrative example, the following four static criteria have been selected:

(1) $V_{\Sigma}$ - total volume of the EMM, including volume of the electric motor, of the clutch and that of the gear reducer: $V_{\Sigma}=V_{\text {mot }}+V_{\text {gear }}+V_{\text {clutch }},\left(\mathrm{mm}^{3}\right)$

(2) $L \times B \times H$ - overall dimensions of the EMM, $\left(\mathrm{mm}^{3}\right)$

(3) $\eta_{\text {total }}$ - total efficiency of the EMM, including the efficiency of the electric motor, of the clutch and of the gear reducer: $\eta_{\text {total }}=\eta_{\text {mot }} \times \eta_{\text {gear }} \times \eta_{\text {clutch }},(-)$

(4) $m_{\text {total }}$ - total weight of the EMM, (kg).

Table 1 Some technical characteristics of the selected electromechanical modules

\begin{tabular}{|c|c|c|c|c|c|c|c|c|}
\hline *alt. No. & manufacturer & GearID & MotID & $i_{\text {calc }}(-)$ & $V_{\Sigma}\left(\mathrm{cm}^{3}\right)$ & $L \times H \times B\left(\mathrm{~cm}^{3}\right)$ & $\eta_{\text {total }}(-)$ & $m(\mathrm{~kg})$ \\
\hline a1 & KEB & G13A & DM80G2 & 23,08 & 6563,00 & 9256,00 & 0,76 & 18,00 \\
\hline a2 & KEB & G22A & DM80G2 & 23,08 & 8152,00 & 12841,00 & 0,77 & 20,00 \\
\hline a3 & KEB & G42A & DM80G2 & 23,08 & 15261,00 & 26633,00 & 0,77 & 35,00 \\
\hline $\mathrm{a} 4$ & KEB & G52A & DM80G2 & 23,08 & 25740,00 & 42197,00 & 0,77 & 60,00 \\
\hline a5 & KEB & F22A & DM80G2 & 23,08 & 9249,00 & 16014,00 & 0,77 & 26,00 \\
\hline a6 & KEB & F23A & DM80G2 & 23,08 & 9249,00 & 16014,00 & 0,77 & 27,00 \\
\hline a7 & KEB & F32A & DM80G2 & 23,08 & 12461,00 & 22173,00 & 0,77 & 28,00 \\
\hline a8 & KEB & K12D & DM80G2 & 23,08 & 7168,00 & 8161,00 & 0,78 & 21,00 \\
\hline a9 & KEB & K33A & DM80G2 & 23,08 & 10987,00 & 16257,00 & 0,77 & 30,00 \\
\hline a10 & KEB & S12A & DM80G2 & 23,08 & 7172,00 & 9455,00 & 0,72 & 19,00 \\
\hline a11 & KEB & $\mathrm{G} 22 \mathrm{~A}$ & DM90SC4 & 11,54 & 9386,00 & 13143,00 & 0,79 & 23,00 \\
\hline a12 & KEB & G32A & DM90SC4 & 11,54 & 12238,00 & 18917,00 & 0,79 & 28,00 \\
\hline a13 & KEB & F22A & DM90SC4 & 11,54 & 10483,00 & 16543,00 & 0,79 & 29,00 \\
\hline a14 & KEB & K23A & DM90SC4 & 11,54 & 8384,00 & 11145,00 & 0,79 & 30,00 \\
\hline a15 & KEB & K33A & DM90SC4 & 11,54 & 10963,00 & 16657,00 & 0,79 & 32,00 \\
\hline a16 & KEB & K53A & DM90SC4 & 11,54 & 23182,00 & 38601,00 & 0,79 & 59,00 \\
\hline a17 & KEB & S22A & DM90SC4 & 11,54 & 9996,00 & 15856,00 & 0,74 & 28,00 \\
\hline a18 & KEB & G12A & DM90SB4 & 11,54 & 8287,00 & 10150,00 & 0,82 & 24,00 \\
\hline a19 & KEB & G32A & DM90SB4 & 11,54 & 12728,00 & 20023,00 & 0,82 & 32,00 \\
\hline a20 & KEB & G42A & DM90SB4 & 11,54 & 16985,00 & 28822,00 & 0,82 & 42,00 \\
\hline a21 & KEB & F22A & DM90SB4 & 11,54 & 10973,00 & 17669,00 & 0,82 & 33,00 \\
\hline a22 & KEB & $\mathrm{K} 12 \mathrm{D}$ & DM90SB4 & 11,54 & 7626,00 & 13084,00 & 0,82 & 28,00 \\
\hline a23 & KEB & $\mathrm{K} 23 \mathrm{~A}$ & DM90SB4 & 11,54 & 8874,00 & 10607,00 & 0,81 & 34,00 \\
\hline a24 & KEB & K33A & DM90SB4 & 11,54 & 11453,00 & 18180,00 & 0,81 & 36,00 \\
\hline $\mathrm{a} 25$ & KEB & $\mathrm{K} 53 \mathrm{~A}$ & DM90SB4 & 11,54 & 23672,00 & 37688,00 & 0,81 & 63,00 \\
\hline a26 & KEB & S22A & DM90SB4 & 11,54 & 10486,00 & 16783,00 & 0,77 & 32,00 \\
\hline a27 & WATT & HG 40S & 3B 90S/L-04E & 11,54 & 8622,00 & 8991,00 & 0,79 & 27,00 \\
\hline a28 & WATT & HG 50A & 3B 90S/L-04E & 11,54 & 11306,00 & 17768,00 & 0,79 & 32,00 \\
\hline a29 & WATT & ASA 46S & 3C 90S/L-04E & 11,54 & 10035,00 & 15283,00 & 0,82 & 33,00 \\
\hline a30 & WATT & SUA 454S & 3B 90S/L-04E & 11,54 & 7885,00 & 6230,00 & 0,74 & 29,00 \\
\hline a31 & WATT & KUA 50A & 3C 90S/L-04E & 11,54 & 10102,00 & 10154,00 & 0,82 & 37,00 \\
\hline a32 & NORD & SK 02 & $90 \mathrm{SH} / 4$ & 11,54 & 10284,00 & 9501,00 & 0,79 & 27,00 \\
\hline a33 & NORD & SK 22 & $90 \mathrm{SH} / 4$ & 11,54 & 17466,00 & 24075,00 & 0,79 & 44,00 \\
\hline a34 & NORD & SK 0282NB & $90 \mathrm{SH} / 4$ & 11,54 & 11217,00 & 14553,00 & 0,79 & 25,00 \\
\hline $\mathrm{a} 35$ & NORD & SK 90121 & $90 \mathrm{SH} / 4$ & 11,54 & 13774,00 & 18408,00 & 0,79 & 49,00 \\
\hline
\end{tabular}


Table 2 Some technical characteristics of the selected electromechanical modules (continuation)

\begin{tabular}{|c|c|c|c|c|c|c|c|c|}
\hline$*$ alt. No. & manufacturer & GearID & MotID & $i_{\text {calc }}(-)$ & $V_{\Sigma}\left(\mathrm{cm}^{3}\right)$ & $L \times H \times B\left(\mathrm{~cm}^{3}\right)$ & $\eta_{\text {total }}(-)$ & $m(\mathrm{~kg})$ \\
\hline a36 & NORD & SK 92372 & 90 SH/4 & 11,54 & 13688,00 & 15691,00 & 0,79 & 33,00 \\
\hline a37 & NORD & SK 12063 & 90 SH/4 & 11,54 & 11928,00 & 12989,00 & 0,74 & 39,00 \\
\hline a38 & KEB & G12A & DM90LC6 & 7,69 & 10247,00 & 10143,00 & 0,75 & 23,00 \\
\hline a39 & KEB & G22A & DM90LC6 & 7,69 & 11835,00 & 13927,00 & 0,75 & 26,00 \\
\hline a40 & KEB & G52A & DM90LC6 & 7,69 & 29424,00 & 45320,00 & 0,75 & 66,00 \\
\hline a41 & KEB & F22A & DM90LC6 & 7,69 & 12933,00 & 17640,00 & 0,75 & 32,00 \\
\hline a42 & KEB & F32A & DM90LC6 & 7,69 & 16145,00 & 22920,00 & 0,75 & 34,00 \\
\hline a43 & KEB & K12D & DM90LC6 & 7,69 & 10132,00 & 12582,00 & 0,76 & 27,00 \\
\hline a44 & KEB & S22A & DM90LC6 & 7,69 & 12445,00 & 16749,00 & 0,7 & 21,00 \\
\hline a45 & KEB & G32A & DM100LX8 & 5,77 & 14970,00 & 21530,00 & 0,67 & 35,00 \\
\hline a46 & KEB & G42A & DM100LX8 & 5,77 & 19227,00 & 30740,00 & 0,67 & 49,00 \\
\hline a47 & KEB & F32A & DM100LX8 & 5,77 & 16427,00 & 26219,00 & 0,67 & 42,00 \\
\hline a48 & KEB & K33A & DM100LX8 & 5,77 & 13695,00 & 19267,00 & 0,67 & 43,00 \\
\hline a49 & KEB & K43A & DM100LX8 & 5,77 & 17752,00 & 27892,00 & 0,67 & 52,00 \\
\hline
\end{tabular}

* Note: In the above table, the following designations are used: - DM90SC6 - asyn. squirrel cage motor series DM, size 90S, 6-pole.

- Alt. No. - designation for the alternatives

- HG 40S - helical gear unit coaxial, size 40, 2-stage

- manufacturer - name of manufacturer

ASA 46S - shaft mounted gear unit with parallel shafts, size 46, 2-stage

- GearID - geared reducer identification

- SUA 454S - helical worm gear unit, size 454, 2-stage

- MotID - electric motor identification

- KUA 50A - helical bevel gear unit, size 50, 2-stage

- $i_{\text {calc }}(-)$ - calculated value of the gear reducer ratio

- G33 - helical gear unit coaxial, size 3, 3-stage

SK 02 - helical gear unit coaxial, size 02

- K43 - helical bevel gear unit, size 4, 3-stage

SK 9012.1 - helical bevel gear unit

- F33 - helical gear unit with parallel shafts, size 3, 3-stage

SK 12063 - helical worm gear reducer.

- S22 - helical worm gear unit, size 2, 2-stage

Table 3 Values for the indifference and preference thresholds for every criterion, type of function and weights coefficients

\begin{tabular}{|c|c|c|c|c|c|c|}
\hline & & & \multicolumn{4}{|c|}{ Criteria } \\
\hline & & & $\mathrm{k} 1$ & $\mathrm{k} 2$ & $\mathrm{k} 3$ & $\mathrm{k} 4$ \\
\hline & & & $V_{\Sigma}\left(\mathrm{cm}^{3}\right)$ & $L \times H \times B\left(\mathrm{~cm}^{3}\right)$ & $\eta_{\text {total }}$ & weight $(\mathrm{kg})$ \\
\hline & & & \multicolumn{4}{|c|}{ Extremum } \\
\hline & & & $\min$ & $\min$ & $\max$ & $\min$ \\
\hline \multirow{5}{*}{ Example 1} & \multirow{4}{*}{ PROMETHEE } & type of function & $\mathrm{V}$ & $\mathrm{V}$ & $\mathrm{V}$ & $\mathrm{V}$ \\
\hline & & $q$ & 2000,00 & 3000,00 & 0,68 & 15,00 \\
\hline & & $p$ & 8000,00 & 9000,00 & 0,72 & 32,00 \\
\hline & & weights & \multicolumn{4}{|c|}{ equal importance } \\
\hline & RAZOR & weights & \multicolumn{4}{|c|}{ equal importance } \\
\hline \multirow{5}{*}{ Example 2} & \multirow{4}{*}{ PROMETHEE } & type of function & $\mathrm{V}$ & $\mathrm{V}$ & $\mathrm{V}$ & $\mathrm{V}$ \\
\hline & & $q$ & 2000,00 & 3000,00 & 0,68 & 15,00 \\
\hline & & $p$ & 8000,00 & 9000,00 & 0,72 & 32,00 \\
\hline & & weights & \multirow{2}{*}{0,12} & \multirow{2}{*}{0,16} & \multirow{2}{*}{0,44} & \multirow{2}{*}{0,28} \\
\hline & RAZOR & weights & & & & \\
\hline \multirow{5}{*}{ Example 3} & \multirow{4}{*}{ PROMETHEE } & type of function & $\mathrm{V}$ & $\mathrm{V}$ & $\mathrm{V}$ & $\mathrm{V}$ \\
\hline & & $q$ & 7000,00 & 12000,00 & 0,05 & 20,00 \\
\hline & & $p$ & 15000,00 & 20000,00 & 0,12 & 40,00 \\
\hline & & weights & \multicolumn{4}{|c|}{ equal importance } \\
\hline & RAZOR & weights & 0,11 & 0,28 & 0,33 & 0,28 \\
\hline
\end{tabular}

Table 4 Results from the three numerical experiments

\begin{tabular}{|c|c|c|c|c|c|c|}
\hline \multirow{2}{*}{ Alternatives } & \multicolumn{2}{|c|}{ Ranking example 1} & \multicolumn{2}{|c|}{ Ranking example 2} & \multicolumn{2}{|c|}{ Ranking example 3} \\
\hline & RAZOR & PROMETHEE & RAZOR & PROMETHEE & RAZOR & PROMETHEE \\
\hline a1 & 3 & 1 & 9 & 1 & 4 & 3 \\
\hline a2 & 6 & 10 & 12 & 9 & 10 & 9 \\
\hline a3 & 37 & 40 & 36 & 40 & 38 & 38 \\
\hline $\mathrm{a} 4$ & 48 & 47 & 45 & 47 & 48 & 48 \\
\hline a5 & 18 & 16 & 20 & 18 & 20 & 17 \\
\hline a6 & 19 & 17 & 21 & 19 & 22 & 20 \\
\hline a7 & 32 & 35 & 31 & 35 & 32 & 30 \\
\hline a8 & 2 & 2 & 3 & 2 & 2 & 2 \\
\hline a9 & 27 & 24 & 26 & 25 & 28 & 27 \\
\hline a10 & 12 & 4 & 27 & 3 & 16 & 31 \\
\hline a11 & 7 & 14 & 5 & 13 & 6 & 11 \\
\hline a12 & 25 & 32 & 18 & 31 & 24 & 24 \\
\hline a13 & 20 & 23 & 16 & 23 & 18 & 18 \\
\hline a14 & 10 & 8 & 13 & 10 & 11 & 10 \\
\hline a15 & 22 & 26 & 19 & 27 & 23 & 22 \\
\hline a16 & 46 & 46 & 42 & 46 & 45 & 46 \\
\hline a17 & 30 & 20 & 33 & 20 & 31 & 32 \\
\hline a18 & 1 & 6 & 1 & 6 & 1 & 1 \\
\hline a19 & 23 & 34 & 15 & 34 & 19 & 16 \\
\hline a20 & 38 & 43 & 32 & 43 & 37 & 39 \\
\hline a21 & 17 & 28 & 11 & 28 & 14 & 13 \\
\hline a22 & 4 & 12 & 2 & 12 & 3 & 4 \\
\hline a23 & 8 & 11 & 8 & 11 & 8 & 7 \\
\hline
\end{tabular}


Table 5 Results from the three numerical experiments (continuation)

\begin{tabular}{|c|c|c|c|c|c|c|}
\hline \multirow{2}{*}{ Alternatives } & \multicolumn{2}{|c|}{ Ranking example 1} & \multicolumn{2}{|c|}{ Ranking example 2} & \multicolumn{2}{|c|}{ Ranking example 3} \\
\hline & RAZOR & PROMETHEE & RAZOR & PROMETHEE & RAZOR & PROMETHEE \\
\hline $\mathrm{a} 24$ & 24 & 30 & 17 & 33 & 25 & 19 \\
\hline $\mathrm{a} 25$ & 45 & 48 & 41 & 48 & 43 & 47 \\
\hline a26 & 29 & 25 & 29 & 26 & 30 & 28 \\
\hline $\mathrm{a} 27$ & 5 & 5 & 7 & 5 & 5 & 5 \\
\hline a28 & 26 & 29 & 22 & 29 & 26 & 25 \\
\hline a29 & 13 & 21 & 4 & 21 & 12 & 12 \\
\hline $\mathrm{a} 30$ & 14 & 3 & 28 & 4 & 17 & 15 \\
\hline a31 & 11 & 13 & 6 & 14 & 9 & 6 \\
\hline a32 & 9 & 7 & 10 & 8 & 7 & 8 \\
\hline a33 & 40 & 42 & 37 & 42 & 40 & 37 \\
\hline a34 & 15 & 18 & 14 & 16 & 13 & 14 \\
\hline a35 & 36 & 37 & 35 & 38 & 36 & 34 \\
\hline a36 & 31 & 31 & 24 & 30 & 27 & 26 \\
\hline a37 & 35 & 22 & 38 & 22 & 35 & 35 \\
\hline a38 & 16 & 9 & 23 & 7 & 15 & 21 \\
\hline a39 & 28 & 19 & 30 & 17 & 29 & 29 \\
\hline $\mathrm{a} 40$ & 49 & 49 & 49 & 49 & 49 & 49 \\
\hline $\mathrm{a} 41$ & 34 & 33 & 34 & 32 & 33 & 33 \\
\hline $\mathrm{a} 42$ & 39 & 39 & 40 & 39 & 39 & 36 \\
\hline $\mathrm{a} 43$ & 21 & 15 & 25 & 15 & 21 & 23 \\
\hline $\mathrm{a} 44$ & 33 & 27 & 39 & 24 & 34 & 40 \\
\hline $\mathrm{a} 45$ & 41 & 38 & 43 & 37 & 41 & 42 \\
\hline $\mathrm{a} 46$ & 47 & 45 & 48 & 44 & 47 & 45 \\
\hline $\mathrm{a} 47$ & 43 & 41 & 46 & 41 & 44 & 43 \\
\hline $\mathrm{a} 48$ & 42 & 36 & 44 & 36 & 42 & 41 \\
\hline $\mathrm{a} 49$ & 44 & 44 & 47 & 45 & 46 & 44 \\
\hline
\end{tabular}
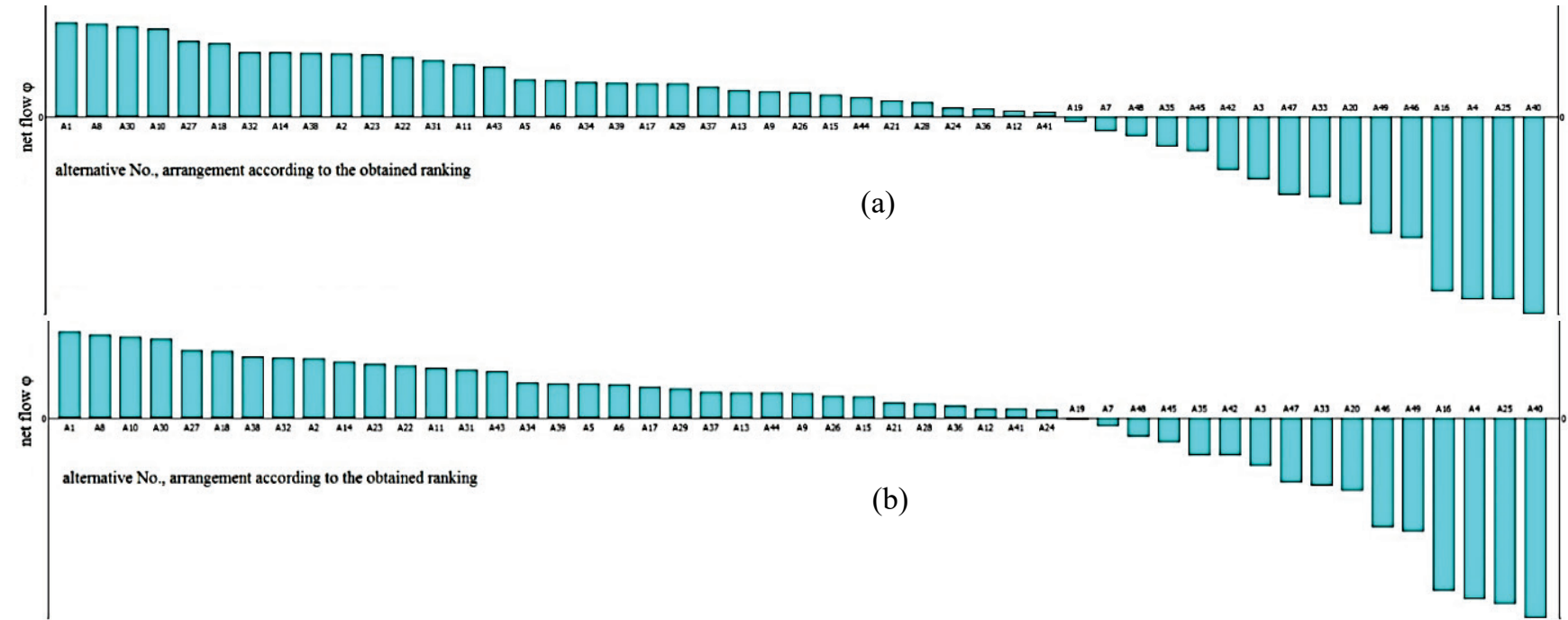

alternative No., arrangement according to the obtained ranking

Figure 4 Graphical representation of the results - PROMETHEE method and Visual PROMETHEE Academic Edition, a) Example 1; b) Example 2; c) Example 3

Three numerical experiments have been conducted using Visual PROMETHEE Academic Edition and MATLAB 2014b. To solve the multi-criteria optimization using RAZOR method, a Simulink model based on its stepwise procedure has been built.

Tab. 2 shows all the relevant information needed to conduct the numerical experiments. The ranking of the alternatives is presented in Tab. 3 and their graphical representation is shown in Fig. 4 and Fig. 5. 

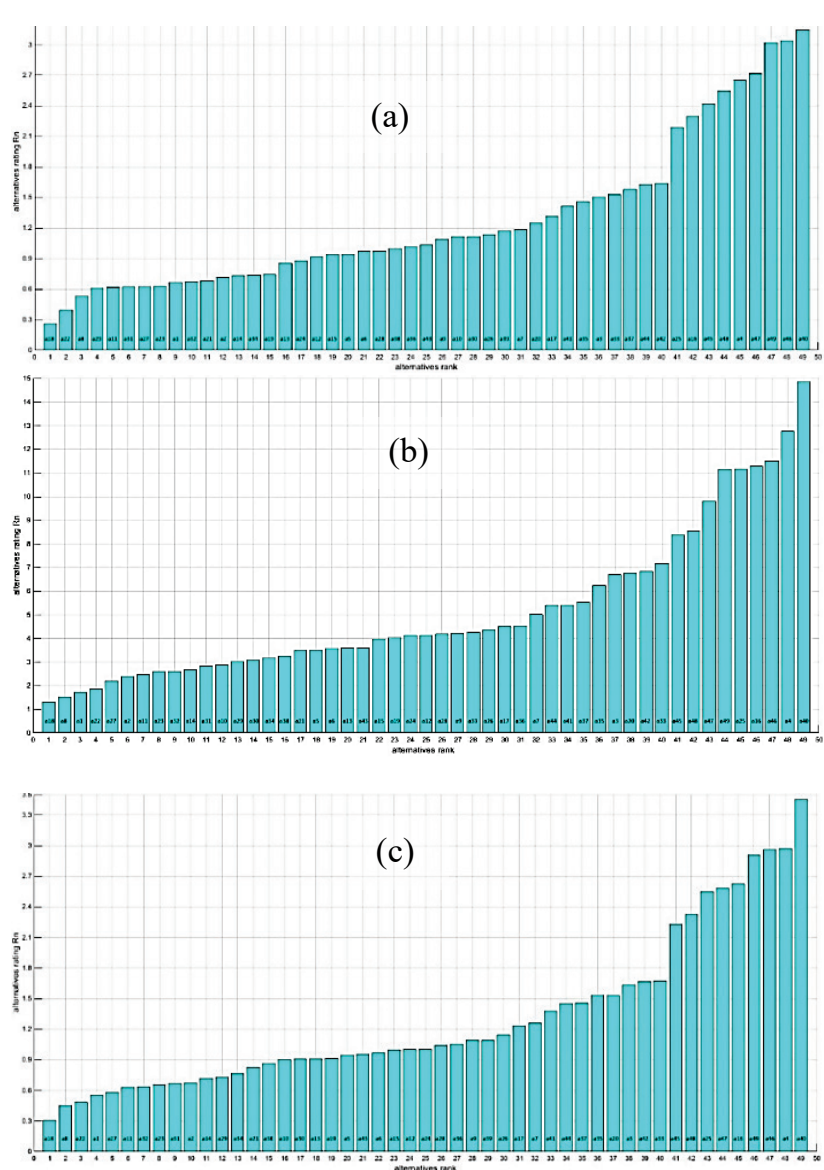

Figure 5 Graphical representation of the results - RAZOR method and MATLAB, (a) Example 1; (b) Example 2; (c) Example 3

\section{ANALYSIS OF THE RESULTS}

As can be observed from Tab. 3, the results show a number of variations in the ranking of the alternatives, which are more prominent in the case of Example 1 and Example 2. The following two main reasons for these deviations can be pointed out:

(1) Difference in the used software: Visual PROMETHEE was used to solve multi-criteria optimization in PROMETHEE method. Though MATLAB 2014b and its Simulink environment offer a wide variety of tools and functions in solving multi-criteria optimization tasks, its optimization toolbox does not provide means of solving such tasks using RAZOR method.

(2) Differences in the methodologies of the used optimization methods:

- RAZOR method is based entirely on mathematical calculations that reduce role of the decision-maker.

- The ranking, obtained using PROMETHEE method depends, to a large extent, on the preference that the decision-maker defines - selection of type of preference function and values for the corresponding threshold(s).

- In Example 1 there are no weight coefficients defined for the criteria, i.e. the four criteria are of equal importance, because of which both methods establish the ranking based on the comparison of the values for each alternative, as in some cases the difference between these values are very small

In the case of Example 1, PROMETHEE method ranking shows that alternative a18 is to be preferred in comparison with the other alternatives and alternative a8 is ranked second. RAZOR method ranking shows that alternative a1 should be preferred over all other alternatives, and alternative a8 is ranked second, as well. Upon further inspection, it has been noted that the differences in the values for all four criteria of alternatives a1 and a18 are small, which can be pointed out as a reason for the resulting deviations. The same is observed for the alternatives ranked from $1^{\text {st }}$ up to $10^{\text {th }}$ place. In the case of alternatives a3, a4, a16, a20, a25, a33, a40, a45, a46, a47, a48 and a49, the differences between their values for all criteria and the values of the rest alternatives are considerable, based on which they are ranked in the last positions. The example shows small overlapping in the results obtained from the two optimization methods, but mostly deviations in the ranking.

At PROMETHEE method, a tuning of the decisionmakers' preferences can be achieved by changing the values of corresponding threshold(s) and/or introducing weight coefficients for the criteria, as at RAZOR method, this can be done only by introducing weight coefficients. Closer observation of Example 2 shows that the introduction of weight coefficients for all of the criteria changes, in some of the cases very notably, the ranking, compared to Example 1. The deviations in the ranking obtained from the two methods are larger, as alternative a1 is ranked first in the instance of PROMETHEE method, and alternative a18 is again ranked first at RAZOR method.

A change in the ranking is observed in Example 3, as well, which is the result of introducing different values for $\mathrm{q}$ and $\mathrm{p}$, as well as for the weight coefficients. In this case the deviations in the ranking of the two methods have been reduced significantly, as alternative a18 is ranked first and alternative a8 is ranked second, both according to PROMETHEE and RAZOR methods.

\section{CONCLUDING REMARKS}

The two outranking methods, presented in this article can be easily used in solving multi-criteria optimization tasks involving large number of alternatives and involving multi-criteria conditions. The stepwise procedures, in which they are applied, are light and simple to implement in comparison with other methods from the same family and a number of software products can be used to aid and ease the decision-makers' work. Both methods offer good insight into the nature of the optimization tasks, as well as the possibility for geometrical visualization of the results of the ranking in the two-dimensional space.

Although the PROMETHEE method requires to have some preliminary knowledge and experience of selecting suitable type of preference function and values for the corresponding threshold(s), its main advantage is the fine setting possibility of the preferences by the decisionmaker. As main advantages of the RAZOR method it can be pointed out that the calculation procedures are not that demanding and do not require preliminary knowledge. The results of the optimization using this method can also be visualized graphically using a number of software.

Based on the conducted numerical tests, the possibility of manipulating the results to a certain extent has to be noted. This is more prominent in using PROMETHEE, as 
the choices that the decision-maker takes are directly related to the outcome of the optimization.

When it comes to solving multi-criteria optimization tasks, the results of the conducted evaluation using outranking methods offers to the decision-maker a guideline to select the "optimal" solution among others. As seen from the given examples in Section 3, the results can be contradictive, even with defined weights for the criteria. If the decision-maker is still not convinced, as to which alternative should be selected, a further optimization of selected number of alternatives can be conducted, i.e. the optimization task can be divided into several tasks with smaller amount of alternatives, based on the conducted initial optimization. Different methods and approaches can be combined, thereby achieving more precise evaluation, in order to remove any doubts regarding the optimality of one solution over the other.

\section{REFERENCES}

[1] Rothgang, S., Baumhöfer, T., van Hoek, H., Lange, T., De Doncker, R., \& Sauer, D. (2015). Modular battery design for reliable, flexible and multi-technology energy storage systems. Applied Energy, 137, 931-937. https://doi.org/10.1016/j.apenergy.2014.06.069

[2] Moosavian, A. \& Xi, F. (2016). Modular design of parallel robots with static redundancy. Mechanism and Machine Theory, 96(1), 26-37. https://doi.org/10.1016/i.mechmachtheory.2015.08.012

[3] Zhao, H., Peng, Y., \& Li, W. (2013). Revised PROMETHEE II for improving efficiency in emergency response. Procedia Computer Science, 17, 181-188. https://doi.org/10.1016/j.procs.2013.05.025

[4] Wang, P., Liu, Y., Ong, S. K., \& Nee, A. Y. C. (2014). Modular design of machine tools to facilitate design for disassembly and remanufacturing. Procedia CIRP, 15, 443448. https://doi.org/10.1016/j.procir.2014.06.085

[5] Kamali, M. \& Hewage K. (2016). Life cycle performance of modular buildings: a critical review. Renewable and Sustainable Energy Reviews, 62, 1171-1183. https://doi.org/10.1016/j.rser.2016.05.031

[6] Manić, N., Hot, I., Lukić, D. \& Pantić, M. (2016). Application of multicriteria optimization methods in the design of road embankments. Tehnički vjesnik, 23(6), 1665 1672. https://doi.org/10.17559/TV-20150325202514

[7] Krasnov, D. V. (1996). News in drive technology: Modularunit production of geared motors made by the Eberhard Bauer Company. Metallurgist, 40(12), 245 - 246. https://doi.org/10.1007/BF02334662

[8] Zeleni, M. (1998). Multiple criteria decision-making: eight concepts of optimality. Human Systems Management, 17(2), 97-107.

[9] Zopounidis, C. \& Doumpos, M. (2002). Multicriteria classification and sorting methods: a literature review. European Journal of Operational Research, 138(2), 229246. https://doi.org/10.1016/S0377-2217(01)00243-0

[10] Haralambopoulos, D. A. \& Polatidis, H. (2003). Renewable energy projects: structuring a multi-criteria group decisionmaking framework. Renewable Energy, 28(6), 961-973. https://doi.org/10.1016/S0960-1481(02)00072-1

[11] Gardiner, L. \& Steuer, R. (1994). Unified interactive multiple objective programming. European Journal of Operational Research, 74(3), 391-406 https://doi.org/10.1016/0377-2217(94)90219-4

[12] Miettinen, K. \& Mäkelä, M. (2006). Synchronous approach in interactive multiobjective optimization. European Journal of Operational Research, 170(3), 909-922. https://doi.org/10.1016/j.ejor.2004.07.052

[13] PROMETHEE-GAIA. (2011). Preference ranking organization method for enrichment evaluation. A strategy guide for using multicriteria analysis in decision-making / Munier, N., NY: Springer, 65-77.

[14] Murat, S., Kazan, H., \& Coskun, S. (2015). An application for measuring performance quality of schools by using the PROMETHEE multi-criteria decision-making method. Procedia - Social and Behavioural Sciences, 195, 729-738. https://doi.org/10.1016/j.sbspro.2015.06.344

[15] Bagherikahvarin, M. \& Smet, Y. (2016). A ranking method based on DEA and PROMETHEE II. Measurement, 89, 333342. https://doi.org/10.1016/j.measurement.2016.04.026

[16] Chen, T. (2015). An interval type-2 fuzzy PROMETHEE method using a likelihood-based outranking comparison approach. Information Fusion, 25, 105-120. https://doi.org/10.1016/j.inffus.2014.10.002

[17] Jablonsky, J. (2014). MS Excel based software support tools for decision problems with multiple criteria. Procedia Economics and Finance, 2, 251-258. https://doi.org/10.1016/S2212-5671(14)00342-6

[18] Optimal Computing. http://www.optimalcomputing.be/ xtreme-software.php (04.01.2016)

[19] http://www.wardsystems.com/genehunter.asp (10.01.2017)

[20] http://www.solvexl.com/ (08.01.2017)

[21] Little, J. \& Moler, C. The MathWorks, Inc. http:// www.mathworks.com/products/optimization/ (08.01.2017)

[22] Andrianov, A. (2012). Approaches and software for multiobjective optimization of nuclear power structures. Sustainability, 4(4), 21-739. https://doi.org/10.3390/su4040721

[23] Mareschal, B. Visual PROMETHEE software. http://www.promethee-gaia.net/ (05.08.2016)

[24] Bigaret, S., Meyer, P., Veneziano, T., \& Olteanu, A. (2015). The Decision Deck project. http://www.decisiondeck.org/diviz (10.01.2017)

[25] Macharis, C., Springael, J., De Brucker, K., \& Verbeke A. (2004). PROMETHEE and AHP: the design of operational synergies in multicriteria analysis. Strengthening PROMETHEE with ideas of AHP. European Journal of Operational Research, 153(2), 307-317. https://doi.org/10.1016/S0377-2217(03)00153-X

[26] Behzadian, M., Kazemzadeh, R. B., Albadvi, A., \& Aghdasi, M. (2010). PROMETHEE: a comprehensive literature review on methodologies and applications. European Journal of Operational Research, 200(1), 198-215. https://doi.org/10.1016/j.ejor.2009.01.021

[27] Albadvi, A., Chaharsooghi, S., \& Esfahanipour, A. (2007). Decision-making in stock trading: an application of PROMETHEE. European Journal of Operational Research, 177(2), 673-683. https://doi.org/10.1016/j.ejor.2005.11.022

[28] Amaral, T. \& Cost, A. (2014). Improving decision-making and management of hospital resources: an application of the PROMETHEE II method in an emergency department. Operations Research for Health Care, 3(1), 1-6. https://doi.org/10.1016/j.orhc.2013.10.002

[29] Lund, D., Lund, M. (2004). Standard score. Lund Research Ltd., Laerd Statistics. https://statistics.laerd.com/statisticalguides/standard-score.php (08.01.2017)

[30] Gagnon, C., Bigras, J., \& Fouron J. (2016). Reference values and Zscores for pulsed-wave Doppler and M-mode measurements in fetal echocardiography. Journal of the American Society of Echocardiography, 29(5), 448-460. https://doi.org/10.1016/j.echo.2016.01.002

[31] Ronai, C., Hamaoka-Okamoto, A., Baker, A., Ferranti, S., Colan, S., Newburger, J., \& Friedman, K. (2016). Coronary artery aneurysm measurement and $\mathrm{Z}$ score variability in Kawasaki disease. Journal of the American Society of Echocardiography, 29(2), 150-157. https://doi.org/10.1016/j.echo.2015.08.013 
[32] Almamy, J., Aston, J., \& Ngwa, L. (2016). An evaluation of Altman's Z-score using cash flow ratio to predict corporate failure amid the recent financial crisis: Evidence from the UK. Journal of Corporate Finance, 36, 278-285. https://doi.org/10.1016/j.jcorpfin.2015.12.009

[33] Warner, R. (2016). Using Z scores for the display and analysis of data. Optimizing the display and interpretation of data / Amsterdam: Elsevier, 7-52. https://doi.org/10.1016/B978-0-12-804513-8.00002-X

[34] Klein, J. (2014). Assessing university students' achievements by means of standard score ( $\mathrm{Z}$ score) and its effect on the learning climate. Studies in Educational Evaluation, 40, 63-68.

https://doi.org/10.1016/j.stueduc.2013.12.002

\section{Contact information:}

Ina D. NIKOLOVA, PhD student

Technical University of Sofia,

Faculty of Engineering and Pedagogy of Sliven,

bul. "Burgasko shose" 59, 8800 Sliven, Bulgaria

E-mail: inanikolova@yahoo.com

Hirpa G. LEMU, PhD, Professor

University of Stavanger,

Kjell Arholms gate 41, Arne Rettedals Hus,

$\mathrm{N}-4036$ Stavanger, Norway

E-mail: Hirpa.g.lemu@uis.no

Dimitrinka S. DAHTEROVA, PhD, Assoc. Professor

Technical University of Sofia,

Faculty of Engineering and Pedagogy of Sliven,

bul. "Burgasko shose" 59, 8800 Sliven, Bulgaria

E-mail: dimitrinka_sı@yahoo.com

Vanio D. IVANOV, PhD, Assoc. Professor

Technical University of Sofia,

Faculty of Engineering and Pedagogy of Sliven,

bul. "Burgasko shose" 59, 8800 Sliven, Bulgaria

E-mail:vanio_ivanov@tu-sofia.bg 